\title{
3D SIMULATION OF STRESS IN GIRTH WELDING OF PIPELINE
}

\author{
Thermal Analysis of Girth Welding in Pipeline
}

[Bridget Kogo, Dr. Bin Wang, Dr. Mahmoud Chizari]

\begin{abstract}
Welding is the primary joining technology used to make continuous pipelines in the industry. The thermal and mechanical loading in the process has a profound impact on the integrity of the pipeline over its service life. An accurate and thorough assessment is needed on the associated residual stress and its effect on the structural properties of the pipeline. 3D simulations of stress in girth welded pipe sections have been carried out using the Abaqus CAE software in two steps, the first being the thermal modelling with a moving hot spot and added mass whereas the second being the stress or mechanical analysis.

In the Thermal Model, it was observed that the distribution of heat in the heat affected zone (HAZ) was maximal at the apex of the heat flux whereas minimum at the start and end points indicating that heat was trapped in the middle region which is responsible for the fluctuations in the heat distribution in these zones. Contour plots of these results further confirm same pattern of temperature distribution. This further implies that the quantity of heat inputted into the model affects the geometry of the model. The design as well as the diameter of the pipe also affected the geometry. It has therefore been deduced that the convective heat was retained within the welding spool for some length of time approximately 10 seconds in the middle region of the weld prior to cooling. The significance of the radiative heat distribution was also considered in the final result as a result of the cavities present within the model.

Due to insufficient time, the thermal analysis has been projected in this paper. The Stress analysis will follow in due course.
\end{abstract}

Keywords-Weld, Girth Weld, Heat Affected Zone (HAZ), Thermal analysis, Stress and Pipeline (key words)

\section{Introduction}

This particular model entails a two material weldment model consisting of the parent metal and the weld metal, with a Heat Affected Zone (HAZ) being considered. The

\section{Bridget Kogo}

College of Engineering, Design and Physical Sciences/ Brunel University London

United Kingdom

\section{Dr Bin Wang}

College of Engineering, Design and Physical Sciences/ Brunel University London

United Kingdom

\section{Dr Mahmoud Chizari}

College of Engineering, Design and Physical Sciences/ Brunel University London

United Kingdom, specific type of solid element used in this analysis is the 20node quadratic hexahedral elements of type DC3D20, heat transfer brick. [1]. It has been confirmed that temperature field produces thermal strain during the welding process which results in residual stress induced elastoplastic behaviour of the material in response to the transient thermal stresses. (Piekara et al).

The Stress induced from welding is one of the bases for cracking and fracture in welded pipes; which imply that the thorough understanding of this phenomenon will enable accurate prediction of the weld induced stresses and as a result aids the design of welded structures.

The quantity of heat applied to the metal defines the degree of melting and distortion welding stress. The Phase transformation from solid to liquid in the state is also accounted for during the welding process, the latent heat of fusion is used to define heat effects similar to molten metal of the weld pool.

\section{Factors Considered}

\section{Consideration of Factors for Thermal Analysis}

The factors considered while carrying out the modelling of the thermal analysis is the penetration of the Heat Affected Zone (HAZ) of the weld metal into the parent metal. The thermal conductivity of each part of the Finite Element mesh equivalent to the weld passes is taken into account and prior to being positioned, the elements are assigned thermal conductivity of air, which changes to the steel value as soon as they are placed. [51].

The density of the metal and the solidus and liquidus temperatures as well as the specific heat capacity and latent heat capacity are also taken into consideration considering the fact that they are very vital and play major role in determining the thermal analysis of the weld.

\section{Geometry of Model}

The Welding simulation was carried out on X65 Carbon Steel Pipe having an outer diameter of 30 inches $(21.98 \mathrm{~mm})$, and wall thickness of $50 \mathrm{~mm}$. Weld mental that was modelled has same material properties as the parent material. The kind of welding utilized in this analysis is the Girth weld from the first weld bead to the seventh. Figure 1 shows the weld model and the sequence of the welds.

For Weld Model containing the passes in their order of sequence, starting from the Left to the right. The first bead otherwise known as root bead is $1.06 \mathrm{~mm}$ in layer while subsequent beads, are $0.61 \mathrm{~mm}$.

The welding procedure involves the dissolving of the welding and letting to cool thereby leaving behind a solidus connecting parent metal to weld. [1]. 


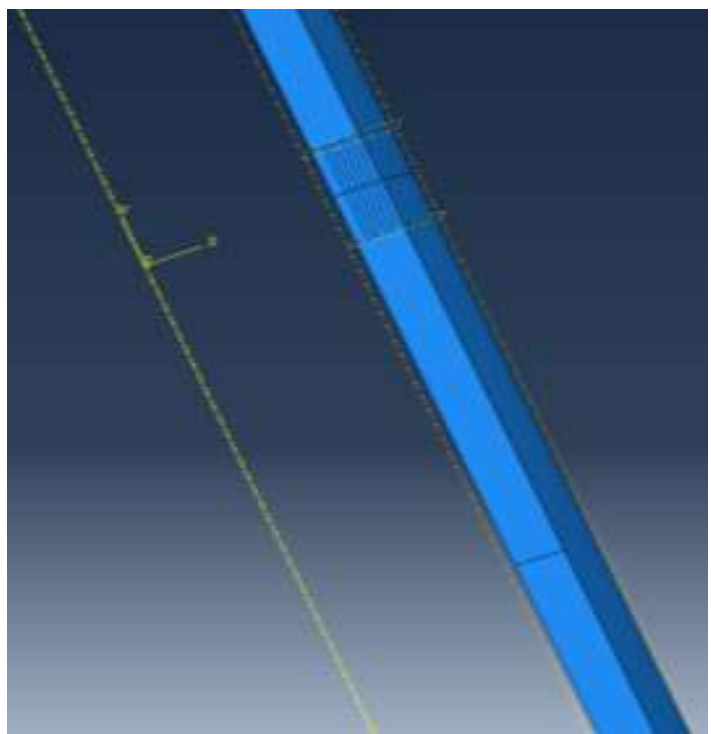

\section{Material Properties}

The material properties of the X65 metal Steel pipe with mass density of $7.97 \mathrm{E}-06 \mathrm{~kg} / \mathrm{m} 3$ have been plotted against the temperature and a single weld metal was used in carrying out this work. The thermal analysis took into consideration the Heat Affected Zone (HAZ) and as such it can be seen from the temperature profiles generated below. The Young Modulus [E], is measured in $\mathrm{m} / \mathrm{kg}$, the Conductivity, The Yield Stress is measured in $\mathrm{Nm} / \mathrm{m}^{2}$, the Liquidus temperature is measured in ${ }^{\circ} \mathrm{C}$ and is of the order of 1400 , the Solidus temperature in ${ }^{\circ} \mathrm{C}$ given as $1375{ }^{\circ} \mathrm{C}$ whereas the Latent heat in $\mathrm{KJ} / \mathrm{kgK}$. The Expansion coefficient is $1.38 \mathrm{E}-05$. The phase transformation which occurred in this analysis is seen is accommodated in the expansion of coefficient alpha given as $1.30 \mathrm{E}$

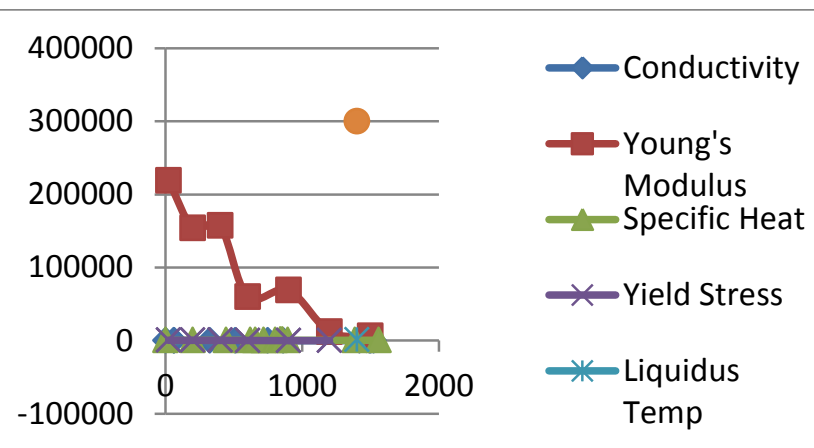

Figure 1: A plot of Material Properties versus Temperature

\section{Thermal Analysis}

Define The Welding procedures encompass step, interaction and load in which the heat flux is applied to each weld pass via convective and radiative mediums of heat transfer. Thus heat steps are created and generated for each pass as well as assigned to a particular section of the weld pool; [3].

A temperature profile across the region of weld in the radial direction is displayed below. Likewise that of the axial direction is also displayed. We can observe a very interesting trend of variation of temperature along the distance from.

Near the expected transformation temperature, there is the display of nonlinearity in the temperature profile. This is due to phase transformation from solid to liquid in the weld pool and further cooling to solid. This process occurs within few minutes and as a result there is irregularity in the temperature profiles. [1].

\section{Results and Discussion}

It has been observed form the thermal profile that the distribution of heat in the heat affected zone was maximal in the apex of the heat flux whereas minimum for each direction of temperature distribution. It therefore means that the quantity if heat inputted into the model affects each of the model. It has also been observed that here is a unique display of Heat flux which means that the flow of heat in each direction is affected by Convection and conduction. [4].

In the radial direction which is seen in figures $3 \mathrm{a}, \mathrm{b}, \mathrm{c}, \mathrm{d}$ and e; the thermal distribution was taken across all heat affected zones (even as far as the parent metal untouched by the heat weld and which remained constantly at room temperature). This further proved the fact that Heat flux differs across heat zones and is affected by the different means of heat transfer. Likewise for the axial direction of heat flow varying thermal profiles were observed in the heat flux. [2].

Thermal Distribution in Radial Direction
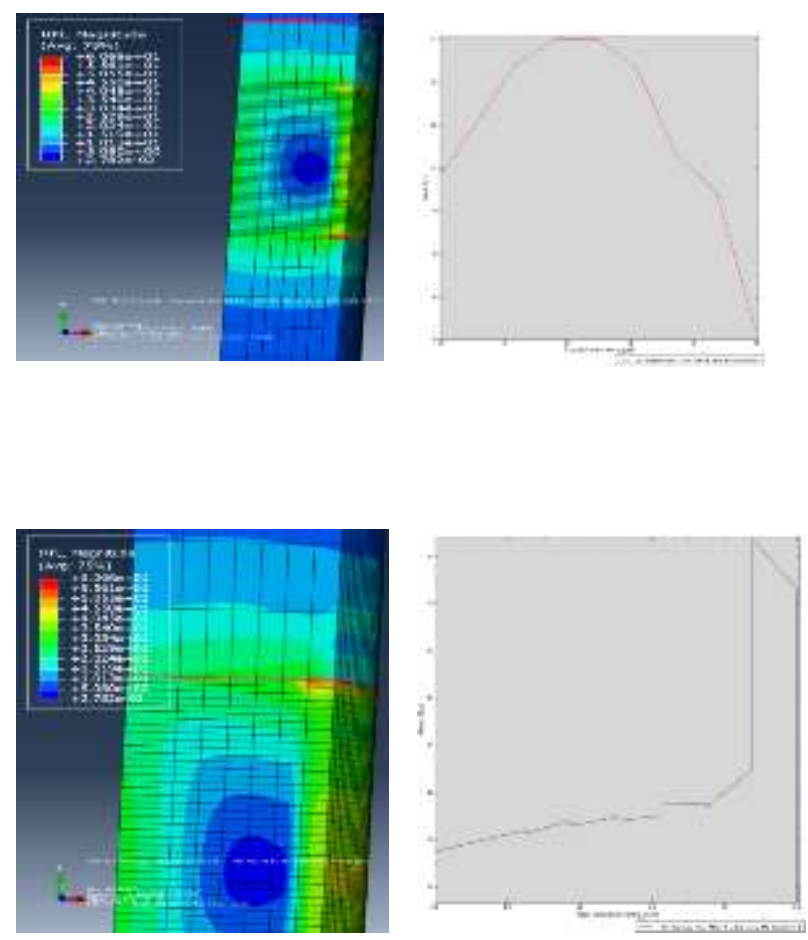
Proc. of the Third Intl. Conf. Advances in Civil, Structural and Mechanical Engineering- CSM 2015

Copyright (c) Institute of Research Engineers and Doctors, USA .All rights reserved.

ISBN: 978-1-63248-062-0 doi: 10.15224/ 978-1-63248-062-0-56
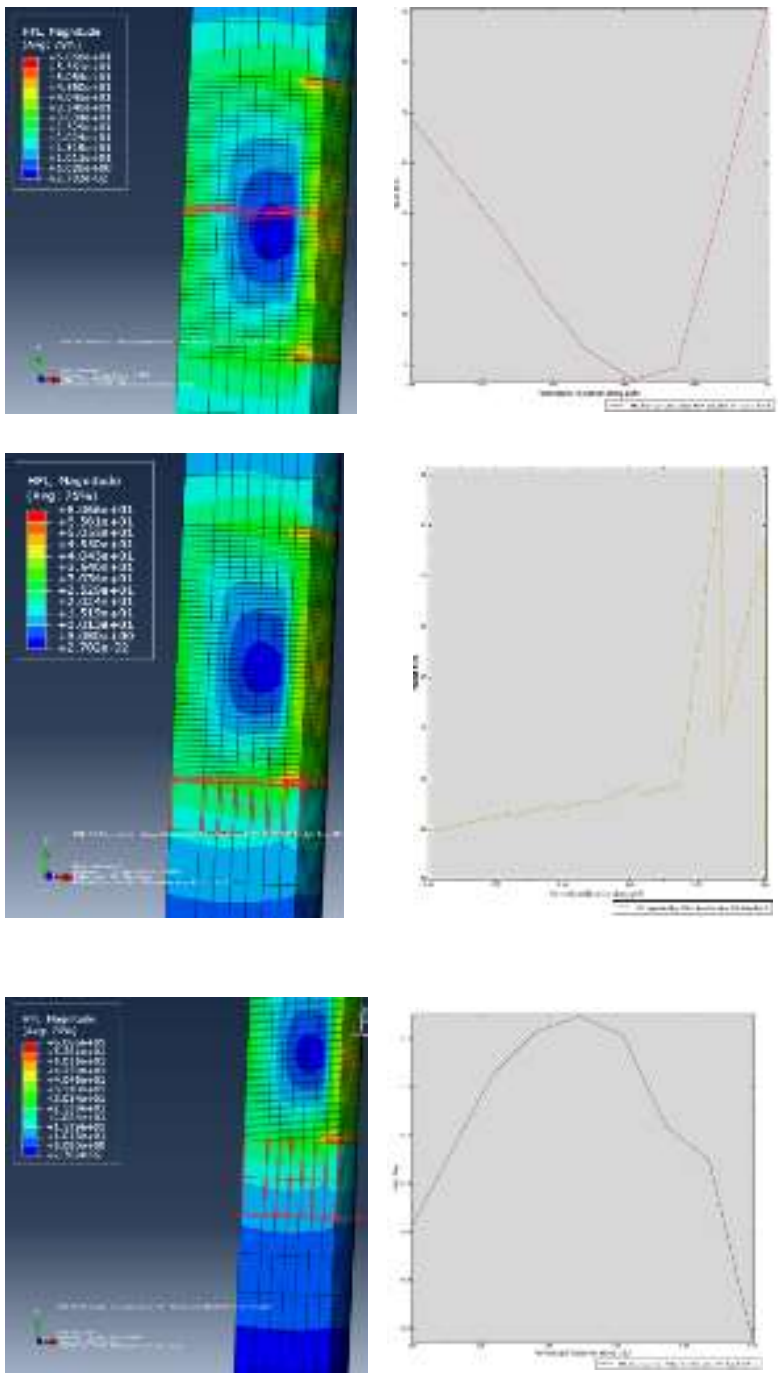

Thermal Distribution in Axial Direction
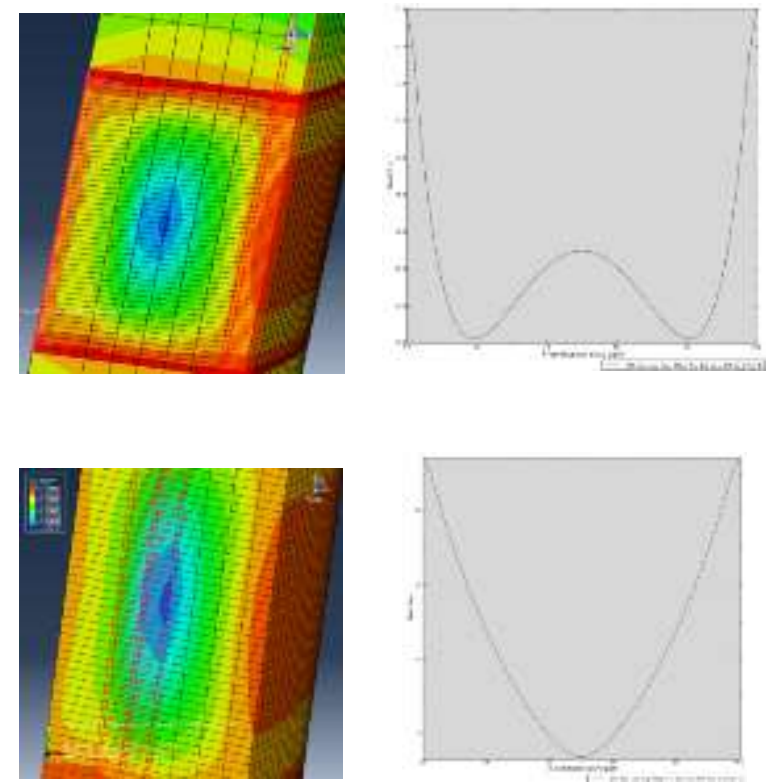
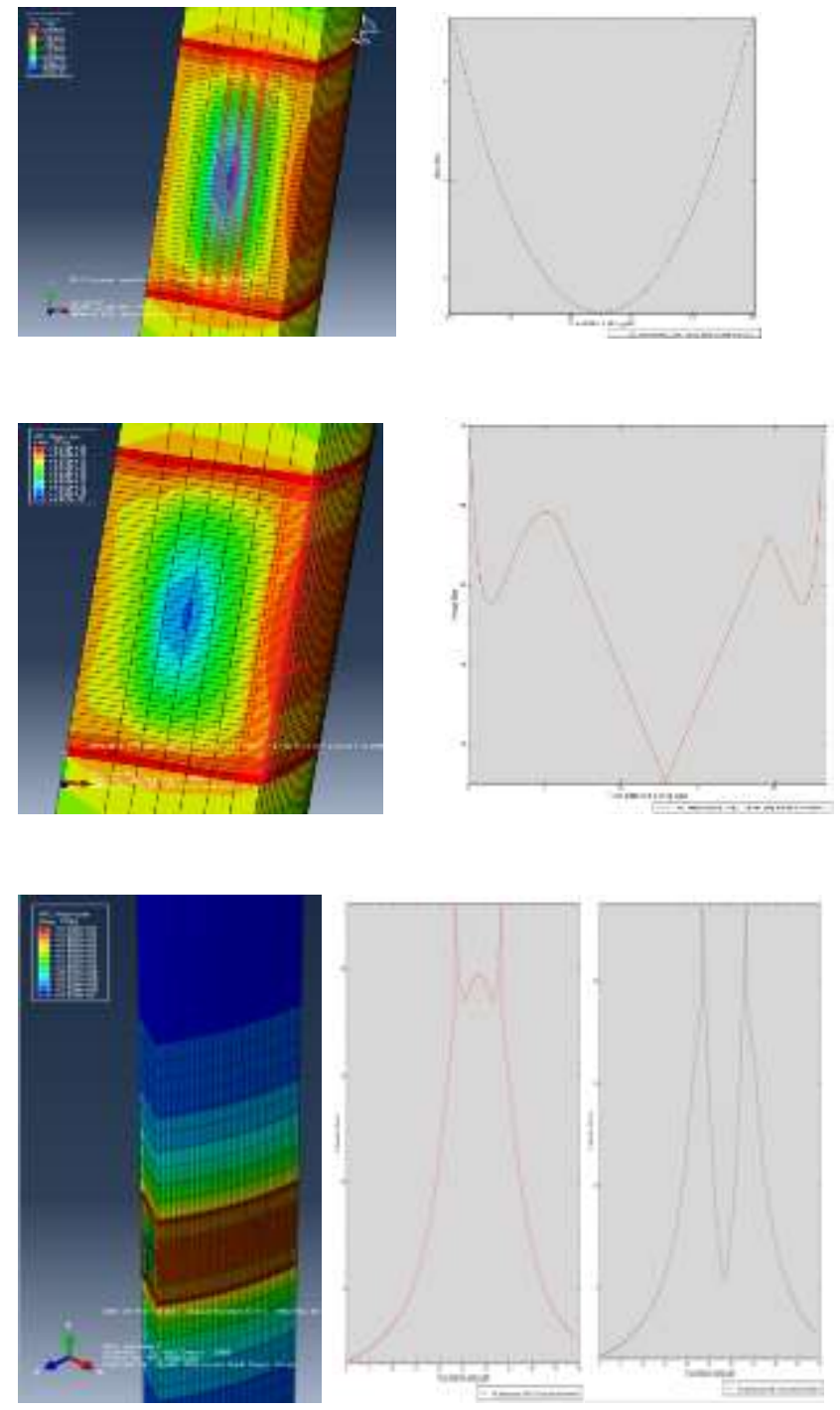

\section{Acknowledgment}

I sincerely thank and appreciate Dr Wang of Brunel University London for his Supervision, encouragements and words of advice. I also want to acknowledge Dr Mahmoud Chizari of Brunel University London for his kind assistance and words of advice.

\section{References}

A. Yaghi, T. H. Hyde, A.A. Becker, W. Sun, J. A. Williams and B. Pathiraj. $5^{\text {th }}$ International Conference on Mechanics and Materials in Design.

C. Acevedo, J. M. Drezet, J. P. Lefebvre, L. D'Alvise and A. Nussbaumer."Residual Stresses in As-Welded Joints: Finite Element Modelling and Neutron Diffraction Stress Measurements" Key Engineering Materials Vols. 488-489 (2012) pp 335-338

L. Wei and W. He Comparison of Measured and Calculated Residual Stresses in Steel Girth and Butt Welds. TWI Ltd, Granta Park, Great Abington, Cambridge

R. H. Leggatt Residual Stresses in Welded Structures. International Journal of Pressure Vessels and Piping 85 (2008) 144-151.

X. Ziwen, Finite Element Modelling of Residual Stress of Welding, Department of Aerospace Engineering, Brunel University London. 


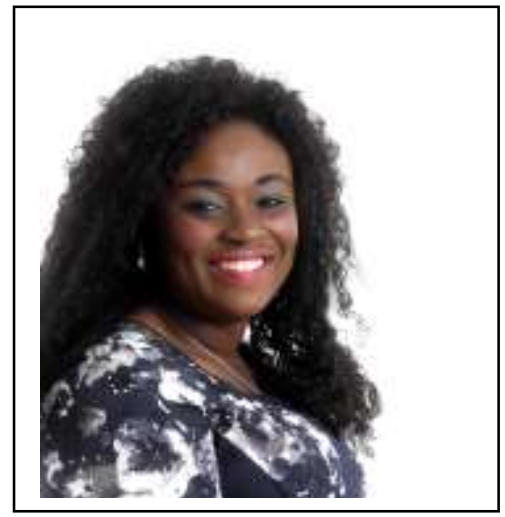

In the Thermal Model, it was observed that the distribution of heat in the heat affected zone (HAZ) was maximal at the apex of the heat flux whereas minimum at the start and end points indicating that heat was trapped in the middle region which is responsible for the fluctuations in the heat distribution in these zones. Contour plots of these results further confirm same pattern of temperature distribution. This further implies that the quantity of heat inputted into the model 